\title{
In silico analysis of Trisindoline 1 compound against Mpro SARS- CoV-2 as novel potential drugs candidate
}

\author{
Fitri Lianingsih 1 \\ ${ }^{1}$ Department of Biology, Faculty of Science and Data Analytics, Institut Teknologi Sepuluh Nopember, Surabaya, Indonesia
}

DOI : https:// doi.org/10.29303/sjp.v2i2.87

\section{Article Info}

Received : 2021-01-31

Revised : 2021-09-12

Accepted : 2021-09-12

\begin{abstract}
The novel coronavirus 2019 (SARS-CoV-2) is one of the viruses that can infect humans and cause high mortality worldwide. The protease (Mpro) is key SARS-CoV-2 an enzyme mediates the viral replication and the transcription. Mpro is currently used as the candidate for the SARS-CoV-2 vaccine because Mpro is one of the key enzymes in the viral life cycle that essential for interactions between the virus and host cell receptor during viral entry. The Mpro can be a target protein to design the novel drug of SARS-CoV-2. The drug design from natural products that are considered to have low toxicity is needed against the virus. The study aims to determines the potential pharmacology of Trisindoline 1 compound from the sponge Hyrtios altum against SARS-CoV-2 and to find the amino acid residues between interaction ligand-protein receptors. The methods of this study use the virtual screening of Auto Dock Vina and visualization the amino acid residue using Bio via Discovery Studio. The result of this study was the selected marine compound from Trisindoline 1 may have potential to developed as inhibitor of SARS-CoV-2.
\end{abstract}

Keywords: In Silico, Mpro, Sars Cov 2, Trisindoline 1, Sponges

Citation: Lianingsih F. (2021). In silico analysis of Trisindoline 1 compound against Mpro SARS-CoV-2 as novel potential drugs candidate. Sasambo Journal of Pharmacy, 2(2), 42-50. doi: https://doi.org/10.29303/sjp.v2i2.87

\section{Introduction}

Coronaviruses are a group of viruses that generally affect the respiratory system of mammals, and can cause acute respiratory infections. The new strain of coronaviruses known as SARS-CoV-2 was originated from Wuhan city, Hubei province of China, in late December 2019 and then later spread across the entire globe (Adhikari et al., 2020). Based on report of WHO, in 5 October 2020, there have been 72,556,942 confirmed cases of COVID-19, including 1,637,155 deaths. As of 16 December, in Indonesia 636,154 confirmed cases of COVID-19, 19,248 deaths and 521,984 recovered cases from 510 districts across all 34 provinces. People with infected coronavirus have some symptoms include fever, cough, difficulty breathing fatigue, headache, nausea, diarrhea runny nose and dyspnea. In more cases, infection coronavirus can cause severe acute respiratory syndrome, vital organ damage and death. There is currently no specifics medicine or treatment for diseases caused by SARS-CoV-2 (Huang et al., 2020).

The characteristics of SARS-CoV-2 are enveloped, positive-sense and single-stranded RNA (Cui et al., 2019). CoVs belonging to the Coronaviridae family of the order Nidovirales, which are divided into four genera ( $a, b, g$, and d). The SARS CoV-2 belongs to the $b$ genus and contain four structural proteins: membrane $(\mathrm{M})$ protein, nucleocapsid $(\mathrm{N})$ protein, Spike (S) protein, and envelope (E) protein (Bosch et al., 2003). Spike protein can promote host attachment and viruses cell membrane fusion during infection of virus. Therefore, Spike determines to some extent the host range (Wu Canrong et al., 2020).

The main protease (Mpro), also known as a chymotrypsin-like cysteine protease, 3CLpro) is one of 
the key enzymes in the viral life cycle that essential for interactions between the virus and host cell receptor during viral entry (Zumla et al. 2016). Mpro are highly conserved, sharing more than $90 \%$ sequence similarity with the corresponding SARS-CoV enzymes (Liu et al., 2020).

Mpro is characterized by a self-cleavage protein and consists of a homodimer subdivided into two protomers (A and B) that have three distinct domains (Cui et al., 2019; Kannan et al. 2020). The first and second domains have antiparallel structure of $\beta$ sheets while the third domain contains five a helices forming a globular group (Jin et al. 2020). Mpro has been found to play a fundamental role in viral gene expression and replication. Therefore, this is the reason Mpro is an attractive candidate target for anti-CoV drug design.

The potential of anti-coronavirus therapies can be divided into two major groups based on the target, one is the human immune system or the coronavirus. Thus, the innate immune system could contribute to control the replication and infection of the coronavirus (Omrani et al., 2014). Blocking the core signal pathways of human immune system or human cells required for virus replication. In addition, the viruses bind to receptor proteins on the surface of cells in order to entering human cells. the SARS virus binds to the angiotensin-converting enzyme 2 (ACE2) receptor to show a certain antiviral effect (Ge XY et al., 2014; Han DP et al., 2006; Li W et al., 2003). Most antiviral drugs are targeted to nucleic acids in viruses. The main problems of viral therapy were to find a drug that specific to fight the virus. Antivirals are more effective in prevention than the treatment in patient (Crumpacker, 2004).

However, no effective antiviral treatment or vaccine is available for COVID-19 until 2021. Presently the SARS-CoV-2 infected patient's treatments have been limited to the use of prophylactic and symptomatic regulation like mild symptoms such as dry cough, sore throat, and fever, and various fatal complications (Chen et al. 2020). Therefore, there is an urgent need for the discovery of a potential treatment therapy and novel drugs from natural product to get effectivity and minimal toxicity against the SARS-CoV2 (Cui et al., 2019).

Natural compounds can be obtained from several plants, microorganisms, and marine organisms (Natalia et al., 2017). Sponges as one of the benthic organisms that are known to contain the most extensive bioactive compounds and get the most attention of researchers compared to other marine invertebrates that have been studied. According to Jha and Zi-Rong (2004), sponges are the largest contributor to bioactive compounds from the sea when compared to other marine biota, namely $37 \%$, followed by coelenterates $(21 \%)$, microorganisms $(18 \%)$, algae $(9 \%)$, echinoderms and tunicates. respectively (6\%), mollusks $(2 \%)$ and bryozoans (1\%).

One of secondary metabolites can derived from sponge. In this study, we conducted selected natural product namely Trisindolina from Hyrtios altum sponges as inhibitor of Mpro in SARS-CoV-2. Trisindoline 1 compound is a natural alkaloid compound originating from the waters of Okinawa, Japan. Trisindolina was isolated from the culture of Vibrio $s p$. which is in symbiosis with the sponge Hyrtios altum. The Trisindolina group has been developed in many recent anticancer studies due to the success of the synthesis method and the high cytotoxic potential (Mustikasari \& Mardi, 2012). Santoso and Mursyidah (2010) have synthesized Trisindolina compound into four. The compound produced by the synthesis of Trisindoline are compound 1 (S1): 5'-nitro- [3,3 ': 3', 3 "-terindoline] -2'one, the synthesis of Trisindoline with the addition of a nitro group, compound 2 (S2), namely 1,1 "-dimethyl5'-nitro- [3,3 ': 3', 3" - terindoline] -2'-one which is the product of Trisindoline with the addition of a dimethyl group, compound 3 (S3) 5,5 ", 7,7 "-tetrabromo- [3,3 ': 3', $3^{\prime \prime}$-terindoline] $-2^{\prime}$-one which is the product of Trisindoline with the addition of a bromo group, and compounds 4 (S4) and 5'-chloro-1,1 "-Diethyl-1H, 1" H[3, $3^{\prime}: 3^{\prime}, 3^{\prime \prime}$-terindol] $-2^{\prime}\left(1^{\prime} \mathrm{H}\right)$-one which is the product of Trisindoline with the addition of a chloro group. The previous study showed that cytotoxicity test of Trisindoline 1 against the MCF cancer cell line showed the highest cytotoxic activity. This means Trisindoline 1 is protential as anticancer (Nurhayati et al., 2017).

Trisindoline belongs to the group of indole alkaloid compounds with a modified addition of a nitro group. The Trisindoline 1 compound also has similarities with the isatin group and its derivatives due to the presence of a heterocyclic ring. A recent study by Zhang et al. (2020) showed that isatin derivatives can act as -keto amide inhibitors are very important inhibitors for MERS and predicted it to be better for SARS-CoV-2 as well. In this study, we selected Trisindoline 1 from sponge to find out the more potential drug of this compounds as antiviral.

Molecular docking is an attractive tool to find out the novel drug design and discovery, as well as in the mechanistic study by a molecule target (ligand) into the binding site of the target specific of the DNA or protein (receptor) with a stable interaction, potential efficacy and more specificity (Rohs et al. 2005; Guedes et al. 2014). The molecular docking approach can be used to model the interaction between a small molecule and a protein at the atomic level with the similarity result reach up 90\% like in vitro result (McConkey et al. 
2002). The basic docking process involves prediction of the ligand conformation with active site and assessment of the binding affinity (Xuan Yu Meng et al. 2011). Prediction of the structure of the ligand complexes with proteins, called protein-ligand docking, is required in the drug development process.

In the present research, the evidence for the potential benefits of Mpro inhibitors against the SARS coronavirus (SARS-CoV-2) is provided. Molecular docking was performed in order to find out the potential of selected compound from Trisindoline 1 as antiviral drug and analysis the amino acid interaction between marine sponge compound and Mpro of SARSCoV-2. This study predicts of potential activity of Trisindoline 1 as antiviral that may inhibit novel coronaviruses and provides scientists with information on compounds that may be effective. This study can continue to anti-viral effects in vitro and in vivo will provide useful information for clinical treatment of novel coronavirus.

\section{Materials and Methods}

The in-silico test was carried out using 2019$\mathrm{nCoV}$ main protease Mpro. The 3D structure is obtained from the protein data bank (www.pdb.org) using the PDB ID: 6lu7. The 3D structure of the target marine sponge compound was draw by Chemdraw. The 3D structure of Lopinavir (Pubchem ID: 92727) and Ritonavir (Pubchem ID: 39262) obtain from PubChem (https://pubchem.ncbi.nlm.nih.gov) and converted by open babel. The energy affinity of the marine sponge compound and Mpro target protein was carried out with Auto dock Vina. The lowest energy affinity is chosen to determine the most potent drug candidate. The interaction between ligands and amino acid residues on the active site was carried out using Bio via Discovery Studio. Furthermore, the study of Mpro that bind to the selected compound was carried out to determine the mechanism of action of the drug candidate. Finally, the protein structure was minimized to Root Mean Square Deviation (RMSD) value with score <2. Thus, analysis of interaction ligand and protein target was done to determine amino acid residues that interact between ligand and protein.

\section{Result and Discussion}

Coronaviruses is presenting major threats to human health over the world (Zhu N et al., 2020). Coronaviruses are a family of positive strand and belongs to enveloped RNA viruses that can cause chronic respiratory and central nervous system diseases in humans (McIntosh, 1974; Marra et al., 2003). This family features the largest viral genomes $(27-31 \mathrm{~kb})$ found to date (Lomniczi, 1977; Lee, 1991). The genomic RNA is formed complexed with the nucleocapsid (N) protein within the membrane with a helical capsid. The membrane of all coronaviruses is must have three viral proteins: (i) a spike protein (S), a type of glycoprotein I, (ii) a membrane protein (M) and (iii) an envelope protein (E). The SARS-CoV genome encode two replicase polyproteins called pp1a $(\sim 450 \mathrm{kDa})$ and pplab $(\sim 750 \mathrm{kDa})$ which produced by a proteolytic process. While other coronaviruses strain make use of three proteases for proteolytic processing, the SARS$\mathrm{CoV}$ encode only two proteases, which include a papain-like cysteine protease (PLpro) and a chymotrypsin-like cysteine protease or 3C-like protease (3CLpro). The 3CLpro enzyme, also called Main protease (Mpro), is indispensable to the viral replication and infection process, thereby making it an ideal target for antiviral therapy (Pillaiyar et al., 2016).

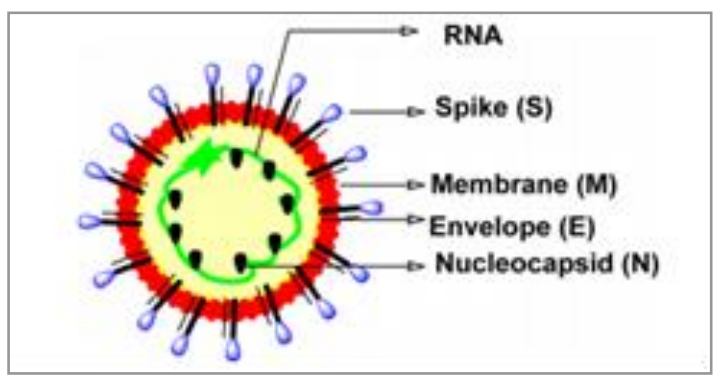

Figure 1. The structure of a corona virus (Pillaiyar et al., 2016).

Currently, no specific clinical therapeutics and vaccine are available for the treatment of SARS-CoV-2mediated infections (Zhou Yet al. 2020). Thus, there is an urgent need to identify and characterize novel drug candidates to overcome the health losses caused by SARS-CoV-2. To provide natural scaffolds for drug development, Trisindoline 1 has selected against novel drug target, Mpro.

The antiviral compounds are needed to be explore since viral diseases have become major human health problems (Sagar et al. 2010; Nannou et al. 2020). The ability of a virus to rapidly evolve, mutant and develop resistance against pharmaceuticals calls for continuing development of the novel antiviral drugs (Rabaan et al. 2020). Several lead antivirals compounds have been isolated from marine natural resources in the worldwide include Indonesia. Based on the previous study, marine natural product chemical family, a sponge-derived bis-indole alkaloid have many bioactivities including antibacterial, antifungal, antiviral, and anti-HIV-1-RTase. The indole-alkaloid based pharmaceutical constitute important class of 
therapeutic agent and can combine with the other pharmaceuticals in the future (Biswal et al., 2012).

Bioinformatics is one of the most essential and straight forward approaches to design new drugs (Lin et al. 2020). Bioinformatics techniques nowadays is very useful because cost effective and easy to use. Due to the high cost of clinical and laboratory trials, the time consuming and the possibility of error the bioinformatics techniques are used to design novel drug potential (Shaghaghi, 2020). Computational docking can be used to predict the conformations and energy affinity of binding for small molecule ligands to protein targets. Docking is widely used for the study of biomolecular interactions and applied to structure based drug design (Vijayaraj et al. 2019).

Auto dock has been used for protein-ligand docking, but very few studies have been performed using nucleic acids and protein as targets (Detering $C$ and Varani G, 2004). Auto dock is a one of the tools for exploration of the nature source to develop the novel drug based on some software like DOCK, FlexX, and GOLD at reproducing the crystallographic pose of ligand-protein binding (Park $\mathrm{H}$ et al., 2006). A search algorithm is initially used to find best conformation of the ligand and protein target, and scoring functions are used for evaluating and show the the "correct" pose (Moitessier et al., 2007). Auto dock performs molecular dockings by calculating energy affinity around the binding site on the target. The algorithm utilizing the Lamarkian Genetic Algorithm (LGA) can be used to find the best energy affinity of the position of the ligand and protein target (Morris et al., 1998; Patrick et al., 2008).

The dock scoring function used to determine the binding site of a ligand, predict the best energy affinity and identify the novel potential drug. Several studies have been conducted to discover 2019-nCoV antiviral drugs (Jin et al. 2020; Sampangi-Ramaiah et al. 2020). The results of some studies shown that protease inhibitors which major part of secondary metabolites derivatives, can be effective to control the viral infection.

The results of virtual screening of target marine sponge compound against Mpro were determined. The bond energies have been tested by RMSD and compared with crystallographic ligands. The marine sponge compound as drug candidates can be done quickly and easily with the help of molecular docking. Virtual screening of drug candidates from natural ingredients helps to discover new molecules and the activity of the targeted compounds.

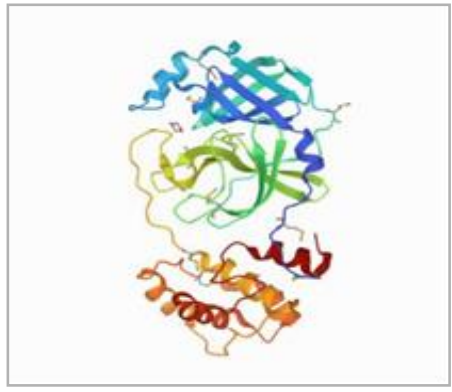

Figure 2. Coronavirus Main Proteinase (3CLpro) Structure with PDB ID : 6LU7 (pdb.org).
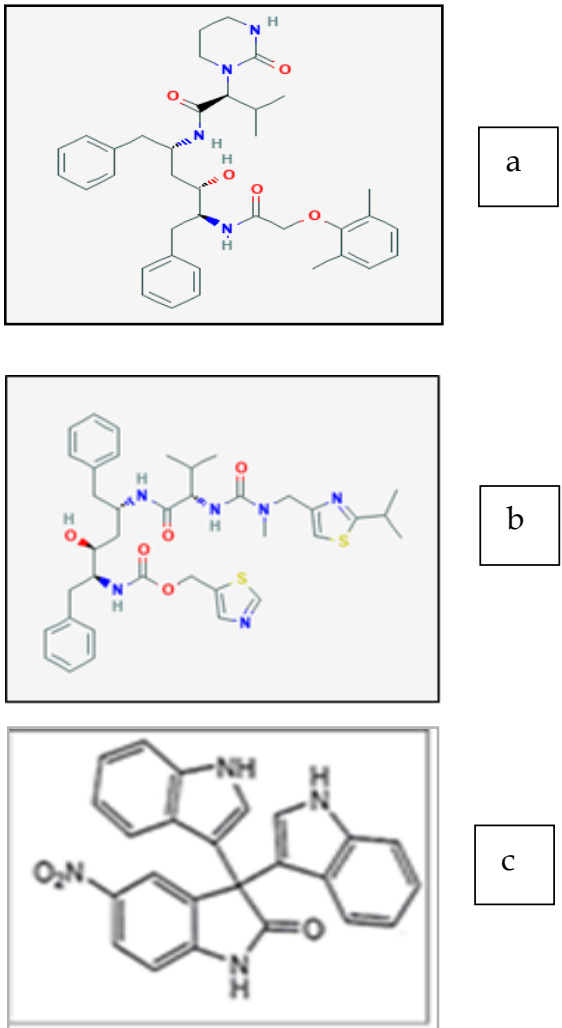

Figure 3. Structure of a) Lopinavir b) Ritonavir c) Trisindoline 1 (5'-nitro-[3,3':3',3'-terindolin]-2'-one)

Docking has been successfully performed between selected marine sponge compound with Mpro. The docking results show that Trisindoline 1 is the most potent compound among other ligand. This is evidenced by the lowest energy affinity value produced on Trisindoline 1 with a score of -8.7 when it binds to Mpro. Based on this study, we can determine the best energy affinity Trisindoline 1 > Lopinavir > Ritonavir. 
Table 1. Docking score selected compound against Mpro

\begin{tabular}{ll}
\hline Ligand & Mpro (N3) kcal/mol \\
\hline Lopinavir & -8.5 \\
\hline Ritonavir & -7.8 \\
\hline Trisindoline 1 & -8.7 \\
\hline
\end{tabular}

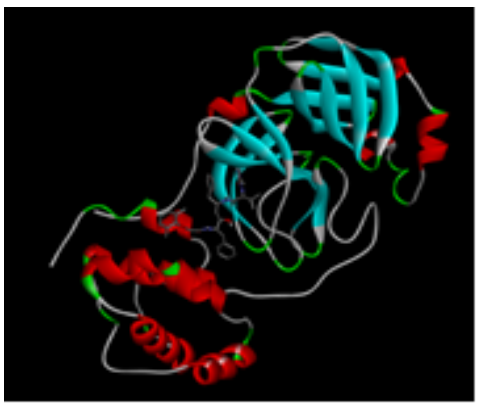

a
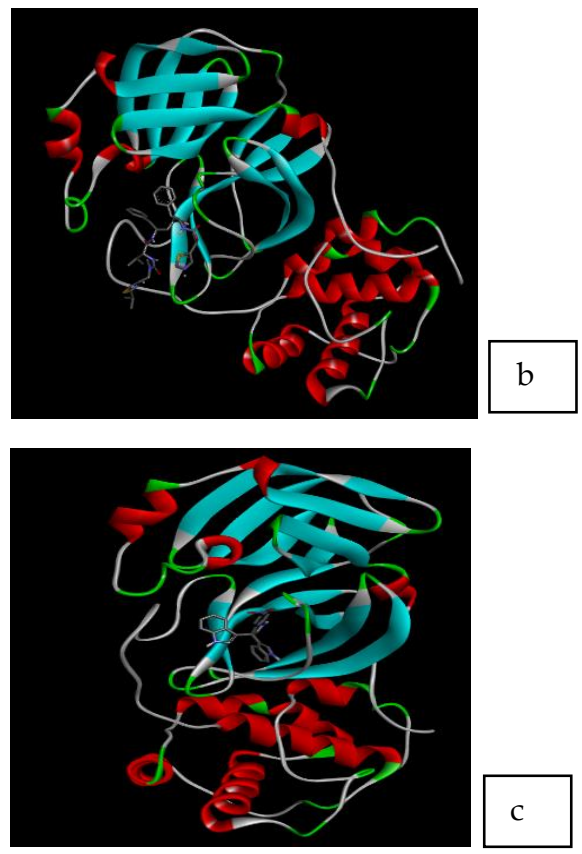

Figure 4. 3D Visualization of Mpro protein and selected ligand a) Lopinavir (Pubchem ID: 92727) b) Ritonavir (Pubchem ID: 39262) c) Trisindoline 1

Trisindoline 1 is classified as indole alkaloid that may can inhibit SARS-Corona virus viral protease 3CL inhibition but the mechanism still undetermined. This compound has similarity with another indole compound like Delavirdine as anti HIV inhibitor. $\mathrm{Xu} \mathrm{H}$ et al. (2009) reported that indole derivatives have potential as a HIV-1 inhibitor. Thus, another indole alkaloid reported that isatin compound which have heterocyclic ring can be role as inhibitors of RTassociated enzymatic functions and HIV-1 reverse transcriptase. The isatin derivatives can be antiviral activity against some viruses like the pox virus, vaccinia virus, rhinovirus, and SARS virus (Varun et al., 2019).

The docking poses of all the ligands were visualized using Bio via Discovery. Three ligands with the highest binding affinity to Mpro were visualized. Lopinavir was interacting with Gln110, Phe294, Val202, Val297, Ile249, and Pro252 residues. The residues of Glu166, Ser144, Asn142, His41, Met49, His163, Met165, and Cys145 binding pocket were responsible for the binding of Ritonavir. Trisindoline 1 showed interaction with Phe140, Leu141, Asn142, Gly143, Ser144, Cys145, His164, His163, Met165, Glu166, His172, and Gln189. The results revealed that the Trisindoline 1 compound fits well in the active site of Mpro and has the highest binding affinity. This compound shows strong interaction with binding site which are responsible for inhibit the activity of Mpro.

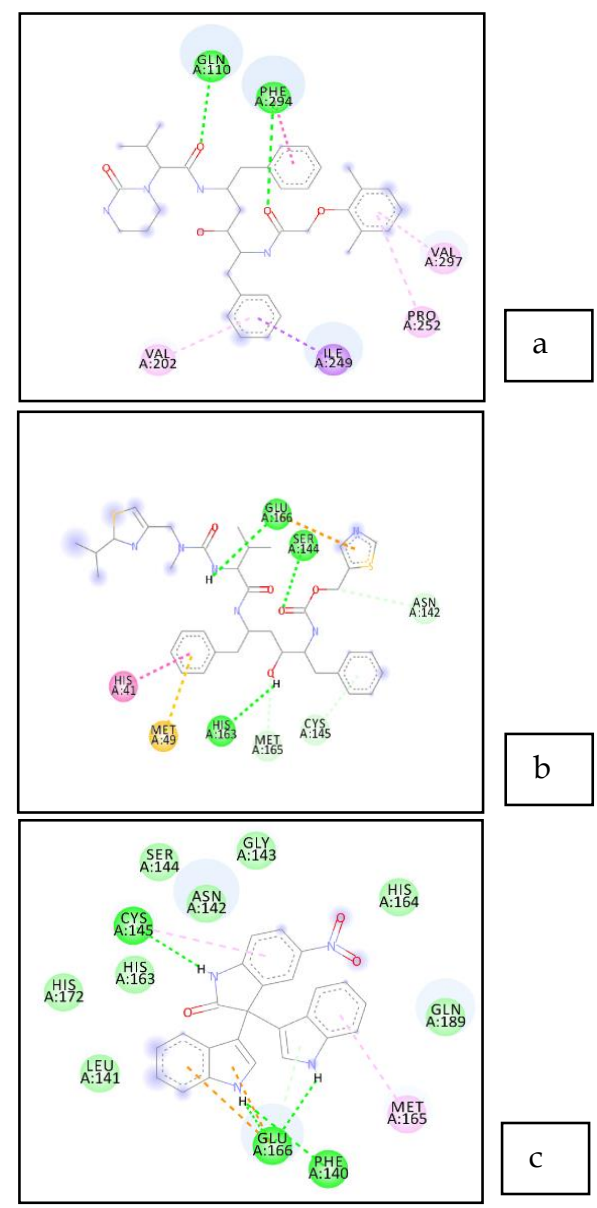

Figure 5. Visualization of interaction amino acid between selected compound against Mpro with ligand a) lopinavir b) ritonavir c) Trisindoline 1 


\section{Conclusion}

In summary, the selected marine compound from sponge can be potential of inhibitor Mpro SARS$\mathrm{CoV}-2$ to develop with another vaccine. The selected marine compound Trisindoline 1 from Hyrtios altum sponge have already been successfully docked against viral disease with potential energy affinity -8.7. Based on this study, Trisindoline 1 compound has potential novel drug as inhibitor of Mpro SARS-CoV-2. This result can continue to study the effectivity of selected marine compound with in vivo and in vitro research. The in-silico technique can be used to study of the potential of novel compound as anticancer, antitumor and antiinflammation. This study is very important to be explore and develop the novel drug as antiviral from nature source in the future. In addition, a multidisciplinary approach (organic chemistry, biochemistry, molecular biology, and molecular genetics) is needed to develop potential of natural product as antiviral drug discovery.

\section{References}

Adhikari, S. P., Meng, S., Wu, Y.-J., Mao, Y.-P., Ye, R.X., Wang, Q.-Z., Sun, C., Sylvia, S., Rozelle, S., Raat, H., \& Zhou, H. (2020). Epidemiology, causes, clinical manifestation and diagnosis, prevention and control of coronavirus disease (COVID-19) during the early outbreak period: A scoping review. Infectious Diseases of Poverty 9(1), 29. 16(1):69. doi : https://doi.org/10.1186/s40249-020-00646-x

Aquilani R, Boselli M, D'Antona G, et al. (2014). Unaffected arm muscle hypercatabolism in dysphagic subacute stroke patients: the effects of essential amino acid supplementation. Biomed Res Int. doi: https://doi.org/10.1155/2014/964365

Aquilani R, Emilio B, Dossena M, Baiardi P, Testa A, Boschi F, Viglio S, Iadarola P, Pasini E, Verri M. (2015). Correlation of deglutition in subacute ischemic stroke patients with peripheral blood adaptive immunity: essential amino acid improvement. Int $J$ Immunopathol Pharmacol 28(4):576-583.doi

https://doi.org/10.1177/0394632015608249

Bosch BJ, van der Zee R, de Haan CA, Rottier PJ. (2003) The coronavirus spike protein is a class I virus fusion protein: structural and functional characterization of the fusion core complex. J Virol ;77: 8801e11. doi : https://doi.org/10.1128/JVI.77.16.8801-8811.2003
Buondonno I, Sassi F, Carignano G, Dutto F, Ferreri C, Pili FG, Massaia M, Nisoli E, Ruocco C, Porrino P, Ravetta C, Riganti C, Isaia GC, D'Amelio P. (2020). From mitochondria to healthy aging: the role of branched-chain amino acids treatment: MATeR a randomized study. Clin Nutr. 39:2080-2091. doi : https://doi.org/10.1016/j.clnu.2019.10.013

Chen N, Zhou M, Dong X, Qu J, Gong F, Han Y, et al. (2020). Epidemiological and clinical characteristics of 99 cases of 2019 novel coronavirus pneumonia in Wuhan, China: a descriptive study. Lancet ;395:50713. doi: https://doi.org/10.1016/s0140$\underline{6736(20) 30211-7}$

Chen YP, Cheng YF, Li XH, Yang WL, Wen C, Zhuang S, Zhou YM. (2017). Effects of threonine supplementation on the growth performance, immunity, oxidative status, intestinal integrity, and barrier function of broilers at the early age. Poult Sci. doi : https://doi.org/10.3382/ps/pew240

Chill L, Rudi A, Aknin M, Loya S, Hizi A, Kashman Y, et al. (2004). New sesterterpenes from Madagascan Lendenfeldia sponges. Tetrahedron, 60, 10619-10626. doi: https://doi.org/10.5681/bi.2011.029

Clive D and Jian Wang. (2003). Stereospecific Total Synthesis of the Antiviral Agent Hamigeran B-Use of Large Silyl Groups to Enforce Facial Selectivity and to Suppress Hydrogenolysis. Angew. Chem. Int. Ed. 42, 3406 - 3409. doi : https://doi.org/10.1002/anie.200351519

Crumpacker CS. (2004). Use of antiviral drugs to prevent herpes virus transmission. New England Journal of Medicine 350:67-68. doi : https://doi.org/10.1056/NEJMe038189

Cui J, Li F, Shi Z-L. (2019). Origin and evolution of pathogenic coronaviruses. Nat Rev Microbiol ;17:18192. doi : https://doi.org/10.1038/s41579-018-0118-9

Detering C, Varani G. (2004). Validation of automated docking programs for docking and database screening against RNA drug targets. J. Med. Chem ;47:4188-4201.

doi: https://doi.org/10.1021/jm030650o

Duan H.Q., Zhang Y.D., Fan K., Suo Z.W., Hu G., Mu X. (2007). Anti-inflammatory mechanism of esculetin. Chin. J. Vet. Med 43:45-46. doi: https://doi.org/10.3390/molecules22030387 
Ge XY, Li JL, Yang XL, Chmura AA, Zhu G, Epstein JH, et al. (2013). Isolation and characterization of a bat SARS-like coronavirus that uses the ACE2 receptor. Nature 2013;503:535e8. doi

https://doi.org/10.1038/nature12711

Guedes IA, de Magalhães CS, Dardenne LE. (2014). Receptor-ligand molecular docking. Biophysical Reviews 6: 75-87. doi : https://doi.org/10.1007/s12551-013-0130-2

Han DP, Penn-Nicholson A, Cho MW. (2006). Identifification of critical determinants on ACE2 for SARS-CoV entry and development of a potent entry inhibitor. Virology ;350:15e25. doi : https://doi.org/10.1016/j.virol.2006.01.029

Hoffmann M, Kleine-Weber H, Schroeder S, Krüger N, Herrler T, Erichsen S, Schiergens TS, Herrler G, Wu NH, Nitsche A, Müller MA, Drosten C, Pöhlmann S. (2020). SARS-CoV-2 Cell Entry Depends on ACE2 and TMPRSS2 and Is Blocked by a Clinically Proven Protease Inhibitor. Cell. doi : https://doi.org//10.1016/j.cell.2020.02.052

Huang C, Wang Y, Li X, Ren L, Zhao J, Hu Y, et al. (2020). Clinical features of patients infected with 2019 novel coronavirus in Wuhan, China. The Lancet ;395:497e506. doi: https://doi.org/10.1016/S0140$\underline{6736(20) 30183-5}$

In Z., Du X., Xu Y., Deng Y., Liu M., Zhao Y., Zhang B., Li X., Zhang L., Peng C., Duan Y., Yu J., Wang L., Yang K., Liu F., Jiang R., Yang X., You T., Liu X., ... Yang H. (2020). Structure of Mpro from SARS-CoV-2 and discovery of its inhibitors. Nature, (7811), 289293. doi : https://doi.org/10.1038/s41586-020-2223y

Kannan S, Shaik Syed Ali P, Sheeza A, Hemalatha K. (2020). COVID-19 (Novel Coronavirus 2019)- recent trends. European Review for Medical and Pharmacological Sciences 24:2006-2011. doi : https://doi.org/10.26355/eurrev_202002_20378

Lin X, Li X, Lin X. (2020). A Review on Applications of Computational Methods in Drug Screening and Design. Molecules. doi https://doi.org/10.3390/molecules25061375

Lira Simone P, Mirna H. R. Seleghim,a David E. Williams,b Frederic Marion,b Pamela Hamill,c François Jean,c Raymond J. Andersen,b Eduardo Hajdud and Roberto G. S. Berlinck. (2007). A SARS-
Coronovirus 3CL Protease Inhibitor Isolated from the Marine Sponge Axinella cf. corrugata: Structure Elucidation and Synthesis. J. Braz. Chem. Soc., Vol. 18, No. 2, 440-443. doi : https://doi.org/10.1590/S0103-50532007000200030

Liu W., Morse J.S., Lalonde, T. Xu S. (2020). Learning from the Past: Possible Urgent Prevention and Treatment Options for Severe Acute Respiratory Infections Caused by 2019-nCoV. ChemBioChem 21, 730-738.

doi:

https://doi.org/10.1002/cbic.202000047

Li W, Moore MJ, Vasilieva N, Sui J, Wong SK, Berne MA, et al. (2003). Angiotensin-converting enzyme 2 is a functional receptor for the SARS coronavirus. Nature ;426:450e4. doi https://doi.org/10.1038/nature02145

Loya Shoshana, Amira Rudi, Yoel Kashman, and Amnon Hizi. (2002). Mode of inhibition of HIV-1 reverse transcriptase by polyacetylenetriol, a novel inhibitor of RNA- and DNA-directed DNA polymerases. Biochem J 15; 362(Pt 3): 685-692. doi : https://doi.org/10.1042/0264-6021:3620685

McConkey BJ, Sobolev V, Edelman M. (2002). The performance of current methods in ligand-protein docking. Current Science 83:845-855. Corpus ID: 15115681

Moitessier N, Englebienne P, Lee D, Lawandi J, Corbeil C. (2007). Towards the development of universal, fast and highly accurate docking/scoring methods: a long way to go. Br. J. Pharmacol ;153:S7- S26. doi : https://doi.org/10.1038/sj.bjp.0707515

Morris GM, Goodsell DS, Halliday RS, Huey R, Hart WE, Belew RK, Olson AJ. (1998). Automated Docking Using a Lamarkian Genetic Algorithm and an Empirical Binding Free Energy Function. J. Comput. Chem ;19:1639-1662. doi: https://doi.org/10.1002/(SICI)1096987X(19981115)19:14<1639::AID-JCC10>3.0.CO;2-B

Muller W, Bohm M, Batel R, De Rosa S, Tommonaro G, Muller I, Schroder H. (2000). Application of cell culture for the production of bioactive compounds from sponges: synthesis of avarol by primmorphs from Dysidea avara. J. Nat. Prod 63:1077-1081. doi : https://doi.org/10.1021/np000003p

Nannou C, Ofrydopoulou A, Evgenidou E, Heath D, Heath E, Lambropoulou D. (2020). Antiviral drugs 
in aquatic environment and wastewater treatment plants: A review on occurrence, fate, removal and ecotoxicity. Sci Total Environ 699:134322. doi : https://doi.org/10.1016/j.scitotenv.2019.134322

Natalia Bailon-Moscoso, Gabriela Cevallos-Solorzano, Juan Carlos Romero-Benavides, and Maria Isabel Ramirez Orellana. (2017). Natural Compounds as Modulators of Cell Cycle Arrest: Application for Anticancer Chemotherapies. Current Genomics 18, 106-131. doi

https://doi.org/10.2174/13892029176661608081256 $\underline{45}$

Omrani AS, Saad MM, Baig K, Bahloul A, Abdul-Matin M, Alaidaroos AY, et al. (2014). Ribavirin and interferon alfa-2a for severe Middle East respiratory syndrome coronavirus infection: a retrospective cohort study. Lancet Infect Dis ;14:1090e5. doi : https://doi.org/10.1016/S1473-3099(14)70920-X

Park H, Lee J, Lee S. (2006). Critical assessment of the automated AutoDock as a new docking tool for virtual screening. Proteins ;65:549-554. doi : https://doi.org/10.1002/prot.21183

Patrick A. Holt, Jonathan B. Chaires, and John O. Trent. (2008). J Chem Inf Model; 48(8): 1602-1615. doi: https://doi.org/10.1021/ci800063v

Peiris JS, Guan Y, Yuen KY. (2004). Severe acute respiratory syndrome. Nature Medicine 10(12 Suppl):S88-97. doi
https://doi.org/10.1038/nm1143

Pillaiyar, Thanigaimalai, Manoj Manickam, Vigneshwaran Namasivayam, Yoshio Hayashi and Sang-Hun Jung. (2016). An Overview of Severe Acute Respiratory Syndrome-Coronavirus (SARSCoV) 3CL Protease Inhibitors: Peptidomimetics and Small Molecule Chemotherapy. J. Med. Chem. 59, 6595-6628.

https://doi.org/10.1021/acs.jmedchem.5b01461

Rabaan AA, Al-Ahmed SH, Sah R, Tiwari R, Yatoo MI, Patel SK, Pathak M, Malik YS, Dhama K, Singh KP, Bonilla-Aldana DK. (2020). SARS-CoV-2/COVID-19 and advances in developing potential therapeutics and vaccines to counter this emerging pandemic virus-a review. Preprints, 2020040075.recent trends. European Review for Medical and Pharmacological Sciences 24:2006-2011. doi : https://doi.org/10.20944/preprints202004.0075.v1
Rohs R, Bloch I, Sklenar H, Shakked Z. (2005). Molecular flexibility in ab-initio drug docking to DNA: binding-site and binding-mode transitions in all-atom Monte Carlo simulations. Nucl Acids Res 33: 7048-7057. doi https://doi.org/10.1093/nar/gki1008

Sagar, S., Kaur, M., and Minneman, K. P. (2010). Antiviral lead compounds from marine sponges. Mar. Drugs 8, 2619-2638. doi : https://doi.org/10.3390/md8102619

Sampangi-Ramaiah MH, Vishwakarma R, Shaanker RU. (2020). Molecular docking analysis of selected natural products from plants for inhibition of SARSCoV-2 main protease. Curr Sci. 118(7):1087. Shaghaghi N. Molecular Docking study of novel COVID-19 Protease with low risk Terpenoides Compounds of Plants. ChemRxiv. doi: https://doi.org/10.18520/cs/v118/i7/1087-1092

Schoeman D, Fielding BC. (2019). Coronavirus envelope protein: current knowledge. Virol J 16, 69 (2019). doi : https://doi.org/10.1186/s12985-019$\underline{1182-0}$

Solerte SB, Gazzaruso C, Bonacasa R, Rondanelli M, Zamboni M, Basso C, Locatelli E, Schifino N, Giustina A, Fioravanti M. (2008). Nutritional supplements with oral amino acid mixtures increases whole-body lean mass and insulin sensitivity in elderly subjects with sarcopenia. Am J Cardiol 101(11A):69E-77E. doi: https://doi.org/10.1016/j.amjcard.2008.03.004

Uzair B, Mahmood Z, Tabassum S. (2011). Antiviral activity of natural products extracted from marine organisms. BioImpacts: BI. 1(4):203. doi : https://doi.org/10.5681/bi.2011.029

Varun, Sonam and Rita Kakkar. (2019). Isatin and its derivatives: a survey of recent syntheses, reactions, and applications. Med. Chem. Commun., 10, 351. doi : https://doi.org/10.1039/C8MD00585K

Vijayaraj, R., Altaff, K., Rosita, A. S., Ramadevi, S., \& Revathy, J. (2020). Bioactive compounds from marine resources against novel corona virus (2019$\mathrm{nCoV})$ : in silico study for corona viral drug. Natural Product Research, 1-5. doi : https://doi.org/10.1080/14786419.2020.1791115

Wellington K.D., Cambie R.C., Rutledge P.S., Bergquist P.R. (2000). Chemistry of sponges, 19: novel bioactive metabolites from Hamigera tarangaensis. J. 
Nat. Prod. 63:79-85. doi :

https://doi.org/10.1021/np9903494

World Health Organization. (2020). WHO Coronavirus Disease (COVID-19). World. Health Organization. Retrieved from https://covid19.who.int/

Xuan-Yu Meng Hong-Xing Zhang, Mihaly Mezei, and Meng Cui. (2011). Molecular Docking: A powerful approach for structure-based drug discovery. Curr Comput Aided Drug Des 1; 7(2): 146-157. doi: https://doi.org/10.2174/157340911795677602

Xu, H.; Lv, M. (2009). Developments of Indoles as AntiHIV-1 Inhibitors. Curr. Pharm. Des. 15. 2120-2148. doi : https://doi.org/10.2174/138161209788489168

Zaki A.M., van Boheemen S., Bestebroer T.M. (2012). Isolation of a novel coronavirus from a man with pneumonia in Saudi Arabia. The New England Journal of Medicine 367:1814-1820. doi : https://doi.org/10.1056/NEJMoa1211721

Zappe A, M.E. Snell B., M.J. Bossard. (2008). PEGylation of cyanovirin-N, an entry inhibitor of HIV. Advanced Drug Delivery Reviews 60 79-87. doi : https://doi.org/10.1016/j.addr.2007.05.016

Zhang, L., Lin, D., Kusov, Y., Nian, Y., Ma, Q., Wang, J., von Brunn, A., Leyssen, P., Lanko, K., Neyts, J., de Wilde, A., Snijder, E. J., Liu, H., \& Hilgenfeld, R. (2020.). a-Ketoamides as broad-spectrum inhibitors of coronavirus and enterovirus replication: Structure-based design, synthesis, and activity assessment. Journal of Medicinal Chemistry, 63(9), 4562-4578. doi : 10.1021/acs.jmedchem.9b01828

Zhou Y, Hou Y, Shen J, Huang Y, Martin W, Cheng F. (2020). Network-based drug repurposing for novel coronavirus 2019-nCoV/SARS-CoV-2. Cell Discovery. doi : https://doi.org/10.1038/s41421-020$\underline{0153-3}$

Zhu N, Zhang D, Wang W, Li X, Yang B, Song J, Zhao X, Huang B, Shi W, Lu R, Niu P, Zhan F, Ma X, Wang D, Xu W, Wu G, Gao GF, Tan W. (2020). A Novel Coronavirus from Patients with Pneumonia in China, 2019. N Engl J Med. 382, 727-733. doi : https://doi.org/10.1056/NEJMoa2001017

Zumla, A.; Chan, J.F.W.; Azhar, E.I.; Hui, D.S.C.; Yuen, K.-Y. (2016). Coronaviruses - Drug discovery and therapeutic options. Nat. Rev. Drug Discov. 15, 327347. doi https://doi.org/10.1038/nrd.2015.37 